\title{
Outcomes in emergency versus elective cases of placenta accreta spectrum disorder managed by caesarean-hysterectomy within a dedicated multidisciplinary care team: retrospective cohort study.
}

\author{
Homero Flores Mendoza ${ }^{1}$, Anjana Chandran ${ }^{2}$, Carlos Hernandez-Nieto ${ }^{3}$, Ally Murji², Lisa \\ Allen $^{2}$, Rory Windrim ${ }^{2}$, John Kingdom ${ }^{2}$, and Sebastian Hobson ${ }^{2}$ \\ ${ }^{1}$ University of Toronto \\ ${ }^{2}$ Mount Sinai Hospital \\ ${ }^{3}$ Iberoamerican Research Network in Obstetrics and Gynecology
}

September 25, 2021

\begin{abstract}
Objective: Compare maternal and perinatal outcomes between emergency and elective caesarean-hysterectomy for placenta accreta spectrum (PAS) disorders managed by a multidisciplinary team. Design and setting: Single-centre retrospective cohort study Population: 125 cases of antenatally suspected and pathologically confirmed PAS disorder. Methods: Maternal and perinatal outcomes were analyzed. Multivariate logistic regression was used to test associations, adjusting for potential confounders. Survival curves exploring risk factors for emergency delivery were sought. Main Outcome Measures: Maternal outcomes including hemorrhagic morbidity, operative complications. Perinatal outcomes included gestational age at delivery, birthweight, Apgar scores and perinatal death. Results: 25 (20\%) and 100 (80\%) patients had emergency and elective delivery, respectively. Emergency delivery had a higher estimated blood loss (median IQR 2772 [2256.75] vs. 1561.19 [1152.95], $\mathrm{p}<0.001$ ), with a higher rate of coagulopathy (40 vs. 6\%; $<<0.001)$ and bladder injury (44 vs. 13\%; p <0.001). Emergency delivery was associated with increased rates of blood transfusion (aOR 4.9, CI95\% 1.3-17.5, p=0.01), coagulopathy (aOR 16.4, CI95\% 2.6-101.4, $\mathrm{p}=0.002$ ) and urinary tract injury (aOR 6.96, CI95\% 1.5-30.7, $\mathrm{p}=0.01$ ). Gestational age at delivery was lower in the emergency group (mean SD 35.19 [2.77] vs. 31.55 [4.75], p=0.001), no difference in perinatal mortality was found (aOR 0.01$, CI95\% < $<.001-17.5, \mathrm{p}=0.53)$. A sonographically short cervix and/or history of APH had an increased cumulative risk of emergency delivery with advancing gestational age. Conclusions: Patients with PAS disorders managed in a tertiary centre by a multidisciplinary team requiring emergency delivery have increased maternal morbidity and poorer perinatal outcomes than those with elective delivery.
\end{abstract}

\section{Introduction}

Placenta accreta spectrum (PAS) is a term that includes varying combinations of abnormal placental implantation that may be accompanied by deficiency of uterine wall integrity ${ }^{1}$. Depending on the degree of adherence to or invasion of the uterine wall and beyond, PAS disorders can be classified as placenta accreta, increta or percreta. An expert consensus grading classification system was recently proposed by the International Federation of Gynaecology and Obstetrics (FIGO) that describes PAS disorders depending on the degree of uterine and parametrial invasion; this classification also includes clinical and histologic criteria for each grade and subtype ${ }^{2}$. The risk of developing a PAS disorder is increased with an increasing number of previous uterine surgeries, predominantly caesarean deliveries; in the presence of placenta previa this risk is significantly higher. Due to the marked increase in caesarean delivery rates across the globe in recent decades, the incidence of PAS disorders has similarly increased ${ }^{3-5}$. 
Over time, the creation of regional specialized multidisciplinary teams dedicated to the management of patients with suspected PAS disorders has demonstrated a progressive reduction is serious maternal morbidity and overall improved outcomes. The emerging expert consensus in many parts of the world is that individuals with PAS disorders, especially those with concomitant placenta previa, should receive care by a dedicated multidisciplinary team with a "Centre of Excellence" 6-7, 1-2.

Comparison of outcomes following emergency versus elective caesarean-hysterectomy by a dedicated and specialized multidisciplinary PAS team has demonstrated significantly poorer outcomes with emergency surgery ${ }^{8}$. In this context, emergency surgery is an independent risk factor for massive blood loss and blood product transfusion requirements ${ }^{9}$. Data comparing maternal and perinatal outcomes between emergency and elective delivery in patients with PAS disorders is presently lacking in Canada. Many facets of care that could vary between countries may ultimately influence this difference, and include: gestational age at elective planned delivery, surgical approaches and experience, protocol-based care, multidisciplinary team member composition, maternal co-morbidities and population demographics. Therefore the objective of this study was to compare maternal and perinatal outcomes between emergency and elective caesarean-hysterectomy for PAS disorders managed by a dedicated and specialized multidisciplinary team in a Canadian tertiary care centre.

\section{Methods}

We conducted a retrospective cohort study of all patients diagnosed with a PAS disorder who underwent either emergency or elective caesarean-hysterectomy in a large Canadian tertiary referral centre over a 12year period. Subjects were identified from a dedicated database of pregnant subjects with PAS managed by our dedicated multidisciplinary care team. Patients with a singleton pregnancy, along with surgically and pathologically-confirmed PAS delivering between July 2007 and December 2019 were included. The elements of multidisciplinary team-based care and the specific elements of our surgical approach have recently been described $^{10}$. The diagnosis of a PAS disorder was made antenatally by the same dedicated PAS team of maternal fetal medicine and radiology specialists using standardized clinical imaging methodology based on second and third trimester ultrasound together with magnetic resonance imaging ${ }^{11}$. Ultrasound findings by abdominal and transvaginal approach suggestive of PAS disorder include: multiple placental lacunae, myometrial thinning, loss of the retroplacental clear space, a bladder bulge, disruption of the echogenic bladder serosa line, aberrant placental and retroplacental hypervascularity and an exophytic mass protruding through the uterine serosa into adjacent organ structures (in cases of severe PAS) ${ }^{12}$. The MRI features of PAS disorder are consistent with those seen by ultrasound and should be read by a radiologist with expertise and experience in diagnosing this particular condition ${ }^{13}$.

In our centre, patients who undergo caesarean-hysterectomy electively are admitted to hospital the day prior to planned delivery at 35-36 weeks' gestation. Earlier admission prior to delivery is considered based on their geographic location of residence, or identified risk factors for preterm birth including recurrent antepartum hemorrhage $(\mathrm{APH})$, shortened cervix, threatened preterm labour and prior preterm birth or prior preterm premature rupture of membranes. Sonographically short cervix was defined as that measuring $<20 \mathrm{~mm}$ transvaginally, in accordance with local and international guidelines ${ }^{14-16}$.

Using hospital electronic medical records, baseline demographics, type of PAS and clinical outcomes were compared between those who underwent elective caesarean-hysterectomy at their scheduled surgery date and those who underwent emergency caesarean-hysterectomy at an earlier unscheduled date as a result of vaginal bleeding, ruptured membranes or persistent uterine contractions. The following maternal metrics were compared: lowest intra-operative hemoglobin, immediate postoperative hemoglobin, estimated blood loss, transfusion of blood-derived products, requirement for general anesthesia, intraoperative complications including attendance of additional surgical services, post-operative ICU admission, length of hospital stay and major post-discharge complications. Perinatal outcomes included mortality and major neonatal morbidity measures.

Continuous variables were tested for normality using visual evaluation of histograms and the Kolmogorov- 
Smirnov test. Continuous data are reported as mean with standard deviation (SD) or as median with interquartile range (IQR) as appropriate. Categorical data are reported as proportions and percentages. Comparisons between groups were made using the Student's $t$-test, Mann-Whitney U test, and chi-squared $\left(\mathrm{x}^{2}\right)$ test or Fisher's exact test, as appropriate. Multivariate logistic regression was used to evaluate associations between independent and dependent variables, adjusting for potential confounders. Kaplan-Meier statistics were used to create a survival curve for delivery and its significance was determined by the log-rank test for factor emergency delivery; additional survival curves exploring risk factors for emergency delivery including sonographic short cervix and history of APH were sought. Statistical analysis was performed with SAS/STAT Software for Windows version 9.4 (SAS Institute Inc., Cary, NC, USA); a P value of $<0.05$ was considered statistically significant.

\section{Results}

One-hundred and twenty-five patients met the inclusion criteria. All subjects had an antenatally suspected and pathologically confirmed PAS disorder. Demographics and baseline characteristics of these participants are presented in Table 1. Twenty-five (20\%) patients underwent emergency caesarean-hysterectomy while one-hundred (80\%) underwent a planned delivery at 35-36 weeks' gestation. The proportion of subjects delivered in each group before a given gestational age is available in Figure S1. Sonographically short cervix prior to delivery was more common in the emergency delivery group compared to the elective group (4\% versus $17.39 \%, \mathrm{p}=0.02)$. The emergency group also had higher rates of maternal thrombophilia and bloodborne viruses (thrombophilia, $4 \%$ versus $0 \%, \mathrm{p}=0.04$; blood-borne virus, $8 \%$ versus $1 \%, \mathrm{p}=0.04$ ). Twenty patients (80\%) in the emergency delivery group had antenatal admission due to APH, while APH was present in $26(26 \%)$ patients in the elective delivery group $(\mathrm{p}<0.01)$. Kaplan-Meier survival curves for those presenting with APH and shortened cervix are shown in Figure 1 and 2. Of note, one patient who had neither a history of short cervix nor APH was delivered emergently at 40 weeks; this patient was a transfer from a local community health centre at the moment of elective caesarean section due to an intraoperative finding of PAS.

Procedure-related maternal morbidity is summarized in Table 2. The emergency delivery group had a significantly lower intraoperative and immediate postoperative haemoglobin compared to the elective delivery group (lowest intraoperative $\mathrm{Hb}$, mean SD 81.16 [20.14] versus 92.94 [16.15] mg/dL, p=0.01; immediate postoperative $\mathrm{Hb}$, mean SD 91.76 [12.16] versus 100.55 [14.59] $\mathrm{mg} / \mathrm{dL}, \mathrm{p}=0.01$ ). Estimated blood loss was significantly higher in the emergency delivery group (median IQR 2772 [2256.75] versus 1561.19 [1152.95] L, $\mathrm{p}=<0.001)$. Fewer units of red blood cells and fresh frozen plasma were transfused in the elective delivery group (red blood cells, median IQR 0 [0-2] versus 3 [0-6] units, $\mathrm{p}=<0.01$; fresh frozen plasma, median IQR 0 $[0]$ versus $0[0-4]$ units, $\mathrm{p}=0.005)$. Cell saver use and salvaged transfusion volumes were higher in the elective compared to the emergency delivery group ( $64 \%$ versus $32 \%, \mathrm{p}=0.003$; cell savage transfusion, median IQR $125[262.5]$ versus $0[0] \mathrm{mL}, \mathrm{p}=0.01)$. General anesthesia was used in $10(40 \%)$ of the emergency and 6 $(6 \%)$ of the elective deliveries $(\mathrm{p}<0.001)$. Intra-operative evidence of coagulopathy was demonstrated in $10(40 \%)$ of the emergency and $6(6 \%)$ of the elective deliveries $(\mathrm{p}<0.001)$. Urologic injury to the bladder occurred in $11(44 \%)$ of the emergency and $13(13 \%)$ of the elective deliveries $(\mathrm{p}<0.001)$. No differences were found in postoperative donor red blood cell units transfused, cryoprecipitate units transfused, platelet units transfused, operative time, need for postoperative embolization or repeat embolization, hysterectomy type performed, need for cardiopulmonary resuscitation, need for vasopressors, ureteric injury or stent placement or injury to the bowel.

Post-procedure maternal morbidity is summarized in Table 3. Admission to the intensive care unit (ICU) was significantly higher in the emergency delivery group (24\% versus $5 \%, \mathrm{p}=0.002)$ and hospital length of stay was longer (median IQR $3[2-4]$ versus 5 [2-8] days) with a higher hemoglobin at discharge (mean SD $99[18]$ versus $85[19] \mathrm{mg} / \mathrm{dL}, \mathrm{p}=0.03)$. Postpartum thromboembolic events complicated more emergency compared to elective deliveries ( $4 \%$ versus $0 \%, \mathrm{p}=0.04$ ). No differences were found in rates of reintervention or readmission, postoperative fever, focal infection complications, transfusion-related acute lung injury, fistula formation, renal failure and urological or gastrointestinal complications. 
Perinatal and neonatal outcomes are available in Table S1. The emergency delivery group had a lower gestational age at delivery compared to the elective delivery group (mean SD 35.19 [2.77] versus 31.55 [4.75] weeks' gestation, $\mathrm{p}=0.001$ ). Mean birthweight was lower in the emergency delivery group compared to the elective delivery group (mean SD 1888.54 [704.5] versus 2679.96 [486.36] g, p<0.001). No differences in mean birthweight percentiles were found, which plotted on the $64^{\text {th }}$ and $65^{\text {th }}$ centile for elective and emergency surgery groups, respectively (Nicolaides, 2018). Median Apgar scores at 5 minutes were also lower in the emergency delivery group compared to the elective delivery group (Apgar 5-minutes, median IQR 9 [0] versus 8 [5-9], $\mathrm{p}<0.001)$, though no differences in mean arterial or venous cord $\mathrm{pH}$ values, or base excess were found. Perinatal death rates, including termination of pregnancy, were higher in the emergency delivery group compared to the elective delivery group $(20 \%$ versus $3 \%, \mathrm{p}=0.001)$. Specific details of these perinatal losses are provided in Table S2.

Multivariate regression analysis, after adjusting for age and other potential confounders, showed significant associations with emergency delivery and increased odds of receiving a blood transfusion (aOR 4.9, CI95\% 1.3-17.5, $\mathrm{p}=0.01$ ), obstetrical hemorrhage (aOR 7.7, CI95\% 1.6-35.6, $\mathrm{p}=0.008$ ), intra-operative coagulopathy (aOR 16.4, CI95\% 2.6-101.4, $\mathrm{p}=0.002$ ) and urinary tract injury (aOR 6.96, CI95\% 1.5-30.7, $\mathrm{p}=0.01$ ). No association was found after adjusting for potential confounders with admission to the ICU (aOR 0.4, CI95\% 0.03-5.8, $\mathrm{p}=0.53$ ) or perinatal death (aOR 0.01, CI95\% $<0.001-17.5, \mathrm{p}=0.53$ ).

\section{Discussion}

Main finding. Patients with PAS disorders managed in a tertiary centre by a dedicated and specialized multidisciplinary team requiring emergency delivery have increased maternal morbidity and poorer perinatal outcomes than those with elective delivery.

Strengths and Limitations. This study has a number of strengths including a relatively large sample size of antenatally suspected and pathologically confirmed patients with PAS disorders, all diagnosed using standardized imagining and clinical methodologies and managed in a single tertiary care centre by the same dedicated multidisciplinary team. Although missing data points are often a limitation in retrospective studies, we avoided this problem as data are continuously collected in a predesigned proforma as per the specific requirements of our ongoing PAS-based research. Despite this, selection and recall bias cannot be excluded. The main limitations of this study relate to the retrospective design of the study ${ }^{17}$. Rare outcomes studied were not able to be generalized and their interpretation may be underpowered to confirm a statistically significant difference.

Interpretation. Improved surgical outcomes with dedicated multidisciplinary management of PAS disorders has been previously demonstrated by many groups worldwide and now forms the basis for recommending regionalized care in many national and international society guidelines ${ }^{18-23,1-2}$. Despite the demonstrated improved outcomes following elective surgery, and a policy of planning such care at 35-36 weeks, a significant proportion of patients with confirmed PAS are at risk of requiring earlier delivery, representing 1 in 5 subjects at our centre over a 12-year period. After adjusting for potential confounders, subjects with PAS disorders delivered emergently were at increased risk for obstetrical hemorrhage, blood transfusion, intraoperative coagulopathy and urinary tract injury. Given the serious nature of these complications, we believe that our findings may justify a more active delivery-planning policy for patients that exhibit the major risk factors of short cervix and/or recurrent APH.

These findings reflect similar observations by other groups focusing on the management of PAS disorders in North America and Europe in the era of "Centres of Excellence" by dedicated and specialized multidisciplinary teams. Outcomes between planned and urgent caesarean-hysterectomy reported by Shamshirsaz et al included an increased composite morbidity, with increased rate of transfusion of blood products and coagulopathy alongside lower Apgar scores and increased respiratory distress syndrome in neonates. These findings are similar in our cohort, with increased rates of transfusion of packed red blood cell units and fresh frozen plasma and similar lower Apgar scores and birthweight in emergency compared to elective deliveries; while the adjusted odds ratio for perinatal death was not significantly different. As in our study, one out- 
come that was more common in the urgent delivery group was intraoperative coagulopathy, which could be explained by increased APH leading to admission or urgent intervention. In our study, the adjusted odds of developing intraoperative coagulopathy during emergency caesarean-hysterectomy was 16 times higher compared to elective delivery. Additionally, we found a difference in lowest intraoperative hemoglobin, intraoperative estimated blood loss and immediate postprocedural hemoglobin in the emergency group, indicative of hemorrhagic morbidity during caesarean-hysterectomy, which was not found in the comparison of urgent and elective deliveries by Shamshirsazet $a l^{8}$. However, this may also be explained by increased episodes of APH leading to antenatal admission in the emergency compared to the elective delivery group in our cohort.

Even before the introduction of specialized and dedicated multidisciplinary team management, the main morbidity in emergent compared to elective PAS disorder management is mainly related to intraoperative surgical blood loss ${ }^{24,25}$. As such, interventions of effective screening and optimized management should be oriented to target this parameter ${ }^{26,27}$. Findings of this study include a 4.9 and 7.7 -fold increased adjusted odds of requiring blood transfusion or encountering massive obstetrical hemorrhage during caesarean-hysterectomy, respectively. Implementation of cell salvage transfusion has been one of the landmarks in the management of obstetrical hemorrhage, particularly in PAS management ${ }^{28-30}$. In our cohort, the use of cell saver was twice as common in the elective delivery group compared to the emergency group with a significantly higher salvage transfusion volume, which highlights the importance of surgery planning and resource allocation in PAS disorders. Another important surgical morbidity is injury to nearby organs, mainly the bladder, which can be performed intentionally to assess the degree of placental invasion or inadvertently as a result of bladder dissection during caesarean-hysterectomy. In one review of 54 cases of PAS disorder invading the bladder, partial cystectomy was performed in 24 of the 54 patients $(44 \%)^{31}$. A large multinational database study comparing planned and emergency delivery including 354 PAS disorder patients reported a bladder injury rate of 4 and $7 \%$, respectively; this difference was not statistically significant $(\mathrm{p}=0.31)$. Injury to other organs and postpartum hematological, infectious or cardiac complications were rare and occurred in less than $2 \%$ of cases $^{32}$. In our study, rates of bladder injury are comparable to those described in the literature and there was a statistically significant higher rate of bladder injury in emergency compared to elective deliveries; when adjusting for potential confounders, the adjusted odds of bladder injury was 6.9 times higher in emergency caesarean-hysterectomy. Another finding of our study is an increased rate of thromboembolism in emergency compared to elective deliveries. This result must be viewed with caution, as it only occurred in 1 case our cohort, in a patient who had an emergency delivery, thus our sample size was underpowered to confirm a statistically significant difference.

Postoperative complications commonly encountered in PAS disorder management include an extended hospital stay and admission to the ICU. Similar to other studies comparing emergency and elective procedures, our findings suggest a significant increase in these variables; nevertheless, when adjusting for age, comorbidities, type of anesthesia and other potential confounders, subjects undergoing emergency delivery were not at an increased adjusted odds of ICU admission ${ }^{33,34}$. Longer length of hospital stay and admission to the ICU could be explained by the use of general anesthetic, which, in addition to intrapartum bleeding, are important factors involved in maternal intraoperative and postoperative morbidity ${ }^{35}$. In our study, emergency compared to elective delivery rates of general anesthetic were significantly higher, reflecting the general trend to perform this procedure under regional when feasible. These findings highlight the importance of a dedicated and specialized multidisciplinary team, including obstetric anesthesiology and critical care in the management of PAS disorders and the importance of the establishment of protocols for elective, but more importantly, emergency cases.

Gestational age for planned delivery in PAS disorders has been a matter of ongoing debate in the literature. Rather than having an arbitrary gestational age window, some authors have advocated for a more individualized and patient-specific risk dependent approach ${ }^{36-39}$. Deciding on elective late preterm versus early term delivery involves balancing neonatal, perinatal and maternal risks and benefits. Earlier gestational ages at elective birth have been proposed, however long-term data regarding neonatal outcomes are lacking. Our relatively low rate of emergency compared to elective delivery and clearly improved maternal outcomes in the latter group, supports planning elective delivery in the late preterm period between 35-36 weeks' 
gestation. Our data demonstrate that individuals with a sonographic short cervix and/or history of APH have an increased cumulative risk of emergency delivery across gestational age, thus it may be reasonable to individualize the scheduled delivery time in this subset of patients with PAS. Patients with placenta previa with or without PAS have been found to have a shorter cervical length in the third trimester, although a correlation with a higher risk of antepartum hemorrhage or preterm birth has been inconsistent ${ }^{40,41}$. The authors acknowledge that individualized and patient-specific risk decision analysis are often part of this complex process; additional data, ideally from prospective trials, are needed to further inform this area.

Conclusions. Our findings suggest that patients with PAS disorders managed in a tertiary centre by a dedicated and specialized multidisciplinary team requiring emergency delivery have poorer outcomes than those with elective delivery. Significantly worse maternal procedure-related outcomes were observed with intraoperative bleeding, development of intraoperative coagulopathy and bladder injury. Postoperatively, this group of subjects had longer hospital stay, higher rates of ICU admission and lower hemoglobin at discharge. Offspring of those requiring emergency delivery had lower Apgar scores and birthweight. Patients with a sonographically short cervix and/or history of APH had an increased cumulative risk of emergency delivery with advancing gestational age. After adjusting for potential confounders, patients with PAS disorders delivered emergently where at increased odds for blood transfusion, obstetrical hemorrhage, intraoperative coagulopathy and urinary tract injury.

Disclosure of interests. None declared.

Contribution to authorship. HFM and SRH conceived and designed the study, analysed the data and wrote the first draft. ARC collected the data. SRH and JCK helped design the objective, contributed to the writing and the analysis, and corrected the manuscript. CHN contributed to the management and analysis of the data. HFM wrote the manuscript and AM, LA, RW, JCK and SRH contributed substantially to the revision of the manuscript for important intellectual content and approved the final version to be published.

Details of ethics approval: This study received approval from the institutional Research Ethics Board (Protocol number17-0162-E).

Funding. None.

\section{References}

1. Hobson SR, Kingdom JC, Murji A, Windrim RC, Carvalho JCA, Singh SS, et al. No. 383-Screening, Diagnosis, and Management of Placenta Accreta Spectrum Disorders. J Obstet Gynaecol Can. 2019 Jul;41(7):1035-1049.

2. Jauniaux E, Alfirevic Z, Bhide AG, Belfort MA, Burton GJ, Collins SL, et al. Placenta Praevia and Placenta Accreta: Diagnosis and Management: Green-top Guideline No. 27a. BJOG. 2019 Jan;126(1):e1-e48.

3. Silver RM, Landon MB, Rouse DJ, Leveno KJ, Spong CY, Thom EA, et al. Maternal morbidity associated with multiple repeat cesarean deliveries. Obstet Gynecol. 2006 Jun;107(6):1226-32.

4. Boerma T, Ronsmans C, Melesse DY, Barros AJD, Barros FC, Juan L, et al. Global epidemiology of use of and disparities in caesarean sections. Lancet. 2018 Oct 13;392(10155):1341-1348.

5. Bailit JL, Grobman WA, Rice MM, Reddy UM, Wapner RJ, Varner MW, et al. Morbidly adherent placenta treatments and outcomes. Obstet Gynecol. 2015 Mar;125(3):683-689.

6. Society of Gynecologic Oncology; American College of Obstetricians and Gynecologists and the Society for Maternal-Fetal Medicine, Cahill AG, Beigi R, Heine RP, Silver RM, et al. Placenta Accreta Spectrum. Am J Obstet Gynecol. 2018 Dec;219(6):B2-B16.

7. Allen L, Jauniaux E, Hobson S, Papillon-Smith J, Belfort MA; FIGO Placenta Accreta Diagnosis and Management Expert Consensus Panel. FIGO consensus guidelines on placenta accreta spectrum disorders: Nonconservative surgical management. Int J Gynaecol Obstet. 2018 Mar;140(3):281-290.

8. Shamshirsaz AA, Fox KA, Erfani H, Clark SL, Shamshirsaz AA, Nassr AA, et al. Outcomes of Planned Compared With Urgent Deliveries Using a Multidisciplinary Team Approach for Morbidly Adherent Placenta. Obstet Gynecol. 2018 Feb;131(2):234-241. 
9. Lasica M, Sparrow RL, Tacey M, Pollock WE, Wood EM, McQuilten ZK; et al. Haematological features, transfusion management and outcomes of massive obstetric haemorrhage: findings from the Australian and New Zealand Massive Transfusion Registry. Br J Haematol. 2020 Aug;190(4):618-628.

10. Kingdom JC, Hobson SR, Murji A, Allen L, Windrim RC, Lockhart E, et al. Minimizing surgical blood loss at cesarean hysterectomy for placenta previa with evidence of placenta increta or placenta percreta: the state of play in 2020. Am J Obstet Gynecol. 2020 Sep;223(3):322-329.

11. Hobson SR, Kingdom JCP, Windrim RC, Murji A, Milligan N, Pacheco JF, et al. Safer outcomes for placenta accreta spectrum disorders: A decade of quality improvement. Int J Gynaecol Obstet. 2021 Apr 23. Epub ahead of print.

12. Comstock $\mathrm{CH}$. Antenatal diagnosis of placenta accreta: a review. Ultrasound Obstet Gynecol. 2005 Jul;26(1):89-96.

13. Familiari A, Liberati M, Lim P, Pagani G, Cali G, Buca D, et al. Diagnostic accuracy of magnetic resonance imaging in detecting the severity of abnormal invasive placenta: a systematic review and meta-analysis. Acta Obstet Gynecol Scand. 2018 May;97(5):507-520.

14. Brown R, Gagnon R, Delisle MF. No. 373-Cervical Insufficiency and Cervical Cerclage. J Obstet Gynaecol Can. 2019 Feb;41(2):233-247.

15. Committee on Practice Bulletins-Obstetrics, The American College of Obstetricians and Gynecologists. Practice bulletin no. 130: prediction and prevention of preterm birth. Obstet Gynecol. 2012 Oct;120(4):964-73.

16. Medley N, Poljak B, Mammarella S, Alfirevic Z. Clinical guidelines for prevention and management of preterm birth: a systematic review. BJOG. 2018 Oct;125(11):1361-1369.

17. Talari K, Goyal M. Retrospective studies - utility and caveats. J R Coll Physicians Edinb. 2020 Dec;50(4):398-402.

18. Yasin N, Slade L, Atkinson E, Kennedy-Andrews S, Scroggs S, Grivell R. The multidisciplinary management of placenta accreta spectrum (PAS) within a single tertiary centre: A ten-year experience. Aust N Z J Obstet Gynaecol. 2019 Aug;59(4):550-554.

19. Erfani H, Fox KA, Clark SL, Rac M, Rocky Hui SK, Rezaei A, et al. Maternal outcomes in unexpected placenta accreta spectrum disorders: single-center experience with a multidisciplinary team. Am J Obstet Gynecol. 2019 Oct;221(4):337.e1-337.e5.

20. Einerson BD, Branch DW. Surgical Management of Placenta Accreta Spectrum. Clin Obstet Gynecol. 2018 Dec;61(4):774-782.

21. Collins SL, Alemdar B, van Beekhuizen HJ, Bertholdt C, Braun T, Calda P, et al. Evidence-based guidelines for the management of abnormally invasive placenta: recommendations from the International Society for Abnormally Invasive Placenta. Am J Obstet Gynecol. 2019 Jun;220(6):511-526.

22. American College of Obstetricians and Gynecologists; Society for Maternal-Fetal Medicine. Obstetric Care Consensus No. 7: Placenta Accreta Spectrum. Obstet Gynecol. 2018 Dec;132(6):e259-e275.

23. Shamshirsaz AA, Fox KA, Erfani H, Clark SL, Salmanian B, Baker BW, et al. Multidisciplinary team learning in the management of the morbidly adherent placenta: outcome improvements over time. Am J Obstet Gynecol. 2017 Jun;216(6):612.e1-612.e5.

24. Gonsoulin W, Kennedy RT, Guidry KH. Elective versus emergency cesarean hysterectomy cases in a residency program setting: a review of 129 cases from 1984 to 1988. Am J Obstet Gynecol. 1991 Jul;165(1):91-4.

25. Lu PY, Pastorek JG 2nd, Letellier RL, Bey MA. Elective versus emergency cesarean hysterectomy on a teaching service-1981 to 1991. South Med J. 1997 Jan;90(1):50-4.

26. Melcer Y, Jauniaux E, Maymon S, Tsviban A, Pekar-Zlotin M, Betser M, et al. Impact of targeted scanning protocols on perinatal outcomes in pregnancies at risk of placenta accreta spectrum or vasa previa. Am J Obstet Gynecol. 2018 Apr;218(4):443.e1-443.e8.

27. Panaiotova J, Tokunaka M, Krajewska K, Zosmer N, Nicolaides KH. Screening for morbidly adherent placenta in early pregnancy. Ultrasound Obstet Gynecol. 2019 Jan;53(1):101-106.

28. Milne ME, Yazer MH, Waters JH. Red blood cell salvage during obstetric hemorrhage. Obstet Gynecol. 2015 Apr;125(4):919-923. 
29. Goucher H, Wong CA, Patel SK, Toledo P. Cell Salvage in Obstetrics. Anesth Analg. 2015 Aug;121(2):465-8.

30. Albright CM, Rouse DJ, Werner EF. Cost savings of red cell salvage during cesarean delivery. Obstet Gynecol. 2014 Oct;124(4):690-696.

31. Sentilhes L, Ambroselli C, Kayem G, Provansal M, Fernandez H, Perrotin F, et al. Maternal outcome after conservative treatment of placenta accreta. Obstet Gynecol. 2010 Mar;115(3):526-534.

32. Morlando M, Schwickert A, Stefanovic V, Gziri MM, Pateisky P, Chalubinski KM, et al. Maternal and neonatal outcomes in planned versus emergency cesarean delivery for placenta accreta spectrum: A multinational database study. Acta Obstet Gynecol Scand. 2021 Mar;100 Suppl 1:41-49.

33. Casele H, Catanzarite V, Holden NE, Poeltler D. Factors influencing maternal outcome after cesarean hysterectomy for placenta accreta, increta and percreta. Am J Obstet Gynecol. 2018 Jan;218(1).S125S126

34. Weissman C, Klein N. The importance of differentiating between elective and emergency postoperative critical care patients. J Crit Care. 2008 Sep;23(3):308-16.

35. Li P, Liu X, Li X, Wei X, Liao J. Clinical outcomes and anesthetic management of pregnancies with placenta previa and suspicion for placenta accreta undergoing intraoperative abdominal aortic balloon occlusion during cesarean section. BMC Anesthesiol. 2020 May 30;20(1):133.

36. Morlando M, Collins S. Placenta Accreta Spectrum Disorders: Challenges, Risks, and Management Strategies. Int J Womens Health. 2020 Nov 10;12:1033-1045.

37. Rac MWF, Wells CE, Twickler DM, Moschos E, McIntire DD, Dashe JS. Placenta accreta and vaginal bleeding according to gestational age at delivery. Obstet Gynecol. 2015 Apr;125(4):808-813.

38. Robinson BK, Grobman WA. Effectiveness of timing strategies for delivery of individuals with placenta previa and accreta. Obstet Gynecol. 2010 Oct;116(4):835-842.

39. Eller AG, Porter TF, Soisson P, Silver RM. Optimal management strategies for placenta accreta. BJOG. 2009 Apr;116(5):648-54.

40. Rac MWF, McIntire DD, Wells CE, Moschos E, Twickler DD. Cervical Length in Patients at Risk for Placenta Accreta. J Ultrasound Med. 2017 Jul;36(7):1431-1436.

41. Stafford IA, Dashe JS, Shivvers SA, Alexander JM, McIntire DD, Leveno KJ. Ultrasonographic cervical length and risk of hemorrhage in pregnancies with placenta previa. Obstet Gynecol. 2010 Sep;116(3):595-600.

Table 1. Participant demographics and baseline characteristics

\begin{tabular}{llll}
\hline Characteristics & $\begin{array}{l}\text { Elective surgery } \\
(\mathbf{n = 1 0 0})\end{array}$ & $\begin{array}{l}\text { Emergency Surgery } \\
(\mathbf{n = 2 5 )}\end{array}$ & $\mathrm{P}$ \\
\hline Maternal age (years) & $34.8 \pm 4.8$ & $34.4 \pm 5$ & 0.7 \\
BMI $\left(\mathrm{kg} / \mathrm{m}^{2}\right)$ & $25.4(6.5)$ & $26.2(5)$ & 0.9 \\
Smoker & $4(4)$ & $2(8)$ & 0.4 \\
ART & $4(4)$ & $1(4)$ & 1 \\
Gravida & $4(2)$ & $4(2)$ & 0.9 \\
Para & $2(2)$ & $2(1)$ & 0.7 \\
Live births & $2(2)$ & $2(1)$ & 0.8 \\
Diabetes & $19(19)$ & $3(12)$ & 0.41 \\
Other medical & $23(23)$ & $6(24)$ & 0.91 \\
conditions & & $1(4)$ & \\
Thrombophilia & $0(0)$ & $0(0)$ & 0.04 \\
Haemoglobinopathy & $1(1)$ & $2(8)$ & 0.6 \\
Blood borne virus & $1(1)$ & $2(1)$ & 0.04 \\
No. of previous CS & $2(1)$ & $7(28)$ & 0.6 \\
Previous D\&C & $33(33)$ & $0(0)$ & 0.63 \\
Other uterine surgeries & $4(4)$ & & 0.3
\end{tabular}




\begin{tabular}{llll}
\hline Characteristics & $\begin{array}{l}\text { Elective surgery } \\
(\mathbf{n = 1 0 0 )}\end{array}$ & $\begin{array}{l}\text { Emergency Surgery } \\
\mathbf{( n = 2 5 )}\end{array}$ & $\mathrm{P}$ \\
\hline $\begin{array}{l}\text { Time since last CS } \\
(\text { mo })\end{array}$ & $40.5(45)$ & $57.5(60)$ & 0.1 \\
Short cervix & $4(4)$ & $4(17.4)$ & 0.02 \\
Placenta previa & $94(94)$ & $24(96)$ & 0.69 \\
APH & $60(60)$ & $19(76)$ & 0.13 \\
$\begin{array}{l}\text { GA at first suspicion of } \\
\text { PAS (wk) }\end{array}$ & $23.3(11.8)$ & $22.0(9.8)$ & 0.7 \\
$\begin{array}{l}\text { Antenatal admission } \\
\text { due to APH }\end{array}$ & $26(26)$ & $20(80)$ & $<0.001$ \\
$\begin{array}{l}\text { Preoperative Hb } \\
\text { (mg/dL) }\end{array}$ & $112.6 \pm 10.4$ & $107.2 \pm 14.5$ & 0.1 \\
\hline
\end{tabular}

BMI, body mass index. ART, assisted reproductive technologies. CS, caesarean section. D\&C, dilation and curettage. APH, antepartum hemorrhage. Hb, hemoglobin. GA, gestational age. PAS, placenta accreta spectrum.

Data are mean \pm SD (independent t-test), median (interquartile range) (Mann-Whitney U test), or n (\%) (x2 test).

Table 2. Procedure-related maternal morbidity

\begin{tabular}{llll}
\hline & $\begin{array}{l}\text { Elective surgery } \\
(\mathbf{n = 1 0 0 )}\end{array}$ & $\begin{array}{l}\text { Emergency Surgery } \\
(\mathbf{n = 2 5})\end{array}$ & $\mathrm{P}$ \\
\hline $\begin{array}{l}\text { Lowest intraoperative } \\
\text { Hb (mg/dL) }\end{array}$ & $92.94 \pm 16.15$ & $81.16 \pm 20.14$ & 0.01 \\
EBL (mL) & $1561.19(1152.95)$ & $2772(2256.75)$ & $<0.001$ \\
$\begin{array}{l}\text { Intraoperative RBC } \\
\text { transfusion }\end{array}$ & $34(34)$ & $19(76)$ & $<0.001$ \\
Intraoperative RBC & $0(2)$ & $3(6)$ & $<0.001$ \\
transfusion (units) & & & \\
Cell saver present at & $64(64)$ & $8(32)$ & 0.002 \\
surgery & & & \\
Cell saver salvage & $125(262.5)$ & $0(0)$ & $<0.001$ \\
transfusion (mL) & & & \\
Cryoprecipitate & $7(7)$ & $2(8)$ & 0.86 \\
transfusion & & & \\
Platelet transfusion & $6(6)$ & $3(12)$ & 0.3 \\
FFP transfusion & $11(11)$ & $8(32)$ & 0.009 \\
Operative time (min) & $157 \pm 81.5$ & $139.5 \pm 89$ & 0.81 \\
Anesthesia epidural & $94(94)$ & $15(60)$ & $<0.001$ \\
Anesthesia general & $6(6)$ & $10(40)$ & $<0.001$ \\
Vasopressor & $9(9)$ & $0(0)$ & 0.11 \\
requirement & & & $<0.001$ \\
Coagulopathy & $6(6)$ & $10(40)$ & $<0.001$ \\
Bladder injury & $13(13)$ & $11(44)$ & 0.61 \\
Ureter injury & $1(1)$ & $0(0)$ & 0.3 \\
Ureter stenting & $4(4)$ & $0(0)$ & 0.28 \\
Bowel injury & $1(1)$ & $1(4)$ & \\
\hline & & & \\
\hline
\end{tabular}


Hb, hemoglobin. EBL, estimated blood loss. RBC, red blood cells. FPP, fresh frozen plasma.

Data are mean \pm SD (independent t-test), median (interquartile range) (Mann-Whitney $\mathrm{U}$ test), or n (\%) (x2 test).

Table 3. Post-procedure maternal morbidity

\begin{tabular}{llll}
\hline & $\begin{array}{l}\text { Elective surgery } \\
(\mathbf{n = 1 0 0 )}\end{array}$ & $\begin{array}{l}\text { Emergency Surgery } \\
(\mathbf{n = 2 5})\end{array}$ & $\mathrm{P}$ \\
\hline $\begin{array}{l}\text { Immediate } \\
\text { postoperative Hb } \\
\text { (mg/dL) }\end{array}$ & $100.55 \pm 14.59$ & $91.76 \pm 12.16$ & 0.006 \\
$\begin{array}{l}\text { Postoperative RBC } \\
\text { transfusion }\end{array}$ & $0(0)$ & & \\
ICU admission & $5(5)$ & $0(0)$ & 0.74 \\
ICU length of stay & $0.06(0.28)$ & $6(24)$ & \\
(days) & & $0.4(1.04)$ & 0.002 \\
Hospital length of stay & $3(1)$ & $5(3)$ & 0.002 \\
(days) & & & \\
Return to OR & $5(5)$ & $2(8)$ & $<0.001$ \\
Postoperative fever & $7(7)$ & $4(16)$ & 0.55 \\
Focal infection & $1(1)$ & $1(4)$ & 0.15 \\
Thromboembolic event & $0(0)$ & $1(4)$ & 0.28 \\
Vascular complications & $3(3)$ & $1(4)$ & 0.04 \\
TRALI & $0(0)$ & $0(0)$ & 0.79 \\
Fistula & $1(1)$ & $1(4)$ & $\mathrm{n} / \mathrm{a}$ \\
Renal failure & $0(0)$ & $0(0)$ & 0.28 \\
Urological & $1(1)$ & $1(4)$ & $\mathrm{n} / \mathrm{a}$ \\
complications & & & 0.28 \\
GI complications & $4(4)$ & $1(4)$ & 1 \\
Psychiatric & $3(3)$ & $1(4)$ & 0.79 \\
complications & & & \\
Hb at discharge (g/L) & $99 \pm 18$ & $85 \pm 19$ & 0.03 \\
Readmission & $7(7)$ & $3(12)$ & 0.4 \\
\hline & & & \\
\hline
\end{tabular}

$\mathrm{Hb}$, hemoglobin. RBC, red blood cells. ICU, intensive care unit. OR, operating room. TRALI, transfusion related acute lung injury. GI, gastrointestinal

Data are mean \pm SD (independent t-test), median (interquartile range) (Mann-Whitney U test), or n (\%) (x2 test).

Table S1. Perinatal and neonatal outcomes

\begin{tabular}{llll}
\hline & $\begin{array}{l}\text { Elective surgery } \\
(\mathbf{n = 1 0 0 )}\end{array}$ & $\begin{array}{l}\text { Emergency Surgery } \\
\mathbf{( n = 2 5 )}\end{array}$ & $\mathrm{P}$ \\
\hline GA at delivery (weeks) & $35.19(2.77)$ & $31.55(4.75)$ & 0.001 \\
Birthweight (grams) & $2679.96 \pm 486.36$ & $1888.54 \pm 704.5$ & $<0.001$ \\
Apgar 1 minute & $8(1)$ & $7(7)$ & $<0.001$ \\
Apgar 5 minutes & $9(0)$ & $8(3)$ & $<0.001$ \\
Cord pH (arterial) & $7.22(0.06)$ & $7.23(0.1)$ & 0.16 \\
Cord BE (arterial) & $1.56 \pm 4.5$ & $1.8 \pm 5.77$ & 0.85 \\
Cord pH (venous) & $7.29(0.05)$ & $7.28(0.1)$ & 0.96
\end{tabular}




\begin{tabular}{llll}
\hline & $\begin{array}{l}\text { Elective surgery } \\
(\mathbf{n = 1 0 0 )}\end{array}$ & $\begin{array}{l}\text { Emergency Surgery } \\
(\mathbf{n = 2 5 )}\end{array}$ & $\mathrm{P}$ \\
\hline Cord BE (venous) & $1.24 \pm 4.06$ & $1.59 \pm 5.16$ & 0.77 \\
Perinatal death & $3(3)$ & $5(20)$ & $<0.001$ \\
\hline
\end{tabular}

GA, gestational age. BE, base excess.

Data are mean \pm SD (independent t-test), median (interquartile range) (Mann-Whitney U test), or n (\%) (x2 test).

Table S2. Perinatal mortality

\begin{tabular}{|c|c|c|c|c|c|}
\hline & Type of delivery & GA & Birthweight (g) & Death cause & Commer \\
\hline Case 1 & Emergency & $23+1$ & 465 & Stillbirth & \\
\hline Case 2 & Emergency & $23+3$ & 480 & Stillbirth & \\
\hline Case 3 & Emergency & $28+6$ & 960 & Stillbirth & \\
\hline Case 4 & Emergency & $19+4$ & Unknown & Stillbirth & \\
\hline Case 5 & Elective & $20+4$ & Unknown & Stillbirth & \\
\hline Case 6 & Elective & $16+5$ & Unknown & Termination of pregnancy & $\mathrm{KCl}$ inje \\
\hline Case 7 & Elective & $30+3$ & 580 & IUFD due to severe FGR & \\
\hline Case 8 & Emergency & $30+2$ & 1550 & Severe neurological depression of unknown etiology & \\
\hline
\end{tabular}

GA, gestational age. g, grams. KCl, Potassium chloride. IUFD, intrauterine fetal death. FGR, fetal growth restriction

\section{Hosted file}

Outcomes in emergency versus elective cases of placenta accreta spectrum disorder managed by Cesarean-h available at https://authorea.com/users/436001/articles/538644-outcomes-in-emergency-versuselective-cases-of-placenta-accreta-spectrum-disorder-managed-by-caesarean-hysterectomywithin-a-dedicated-multidisciplinary-care-team-retrospective-cohort-study

\section{Hosted file}

Outcomes in emergency versus elective cases of placenta accreta spectrum disorder managed by Cesarean-h available at https://authorea.com/users/436001/articles/538644-outcomes-in-emergency-versuselective-cases-of-placenta-accreta-spectrum-disorder-managed-by-caesarean-hysterectomywithin-a-dedicated-multidisciplinary-care-team-retrospective-cohort-study 